\title{
In vitro fibroblast and pre-osteoblastic cellular responses on laser surface modified Ti-6Al-4V
}

Evans Chikarakara ${ }^{1}$, Patricia Fitzpatrick ${ }^{2}$, Eric Moore ${ }^{2}$, Tanya Levingstone ${ }^{3,4}$, Laura Grehan ${ }^{5}$, Clement Higginbotham $^{5}$, Mercedes Vázquez ${ }^{1}$, Komal Bagga ${ }^{1}$, Sumsun Naher ${ }^{6}$ and Dermot Brabazon ${ }^{1}$

${ }^{1}$ Advanced Processing Technology Research Centre, Dublin City University, Glasnevin, Dublin 9, Ireland

${ }^{2}$ Life Science Interface Group, Tyndall National Institute, University College Cork, Cork, Ireland

${ }^{3}$ Tissue Engineering Research Group, Department of Anatomy, Royal College of Surgeons in Ireland, Dublin, Ireland

${ }^{4}$ Advanced Materials and Bioengineering Research (AMBER) Centre, CRANN, Trinity College Dublin, Dublin 2, Ireland

${ }^{5}$ Materials Research Institute, Athlone Institute of Technology, Athlone, Ireland

${ }^{6}$ Department of Mechanical Engineering and Aeronautics, School of Engineering and Mathematical Sciences, City University London,London, UK

\begin{abstract}
The success of any implant, dental or orthopaedic, is driven by the interaction of implant material with the surrounding tissue. In this context, the nature of the implant surface plays a direct role in determining the long term stability as physico-chemical properties of the surface affect cellular attachment, expression of proteins, and finally osseointegration. Thus to enhance the degree of integration of the implant into the host tissue, various surface modification techniques are employed. In this work, laser surface melting of titanium alloy $\mathrm{Ti}-6 \mathrm{Al}-4 \mathrm{~V}$ was carried out using a $\mathrm{CO}_{2}$ laser with an argon gas atmosphere. Investigations were carried out to study the influence of laser surface modification on the biocompatibility of Ti-6Al-4V alloy implant material. Surface roughness, microhardness, and phase development were recorded. Initial knowledge of these effects on biocompatibility was gained from examination of the response of fibroblast cell lines, which was followed by examination of the response of osteoblast cell lines which is relevant to the applications of this material in bone repair. Biocompatibility with these cell lines was analysed via Resazurin cell viability assay, DNA cell attachment assay, and alamarBlue metabolic activity assay. Laser treated surfaces were found to preferentially promote cell attachment, higher levels of proliferation, and enhanced bioactivity when compared to untreated control samples. These results demonstrate the tremendous potential of this laser surface melting treatment to significantly improve the biocompatibility of titanium implants in vivo.
\end{abstract}

Keywords: laser surface melting, fibroblast cells, pre-ostepblastic cells, cell attachment, cell proliferation, biocompatability, beta-phase titanium 


\section{Introduction}

Over the last few decades significant advances have been made in the field of orthopaedic implantation surgery. However, biocompatibility and premature failure of the implants still remains an issue particularly in hard tissue replacements such as total hip implants. The Swedish Total Hip Replacement register reports nearly $75 \%$ of the implants are affected by osteolysis, leading to a re-operation or 'revision' [1]. The main cause of osteolysis is the release of ions due to metal-on-metal wear in bearing surfaces. In an attempt to remove/dissolve the implant debris, the body releases enzymes and other cellular reactions around the implantation site, which causes a chronic inflammatory condition [2]. Since this debris originates from implant surfaces, biocompatibility of implant material becomes the fundamental requirement for choosing a metallic implant; the material has to exhibit properties nontoxic to the surrounding biological system [3].

Titanium and its alloys, especially $\mathrm{Ti}-6 \mathrm{Al}-4 \mathrm{~V}$, are widely used as bone interfacing implant material for both dental and orthopaedic applications due to their excellent mechanical properties, wear and corrosion resistance, and biocompatibility [4-6]. Several studies have revealed that the formation of a stable and strong

oxide layer on the titanium surface in the presence of body fluids favours osseointegration of the implant and the surrounding tissue, thus contributing to prolonged implant lifetime [7,8]. Due to growing global market for orthopaedic implants based on titanium alloys [9], various surface modification techniques have been employed to improve its functionality, durability and biological response by controlling microscopic structure and tuning surface chemistry, topography, roughness, wettability, surface charge and surface energy $[10,11]$. For example, the electron beam melting technique is often employed to increase roughness and attachment of biological cells [12]. By mineralizing the surface with calcium apatite, the interaction between bone and alloy can be improved [13].

Laser gas nitriding and blasting the surface with particles like $\mathrm{Al}_{2} \mathrm{O}_{3}$ or $\mathrm{SiO}_{2}$ leads to increased surface area and imparts resistance to corrosion $[14,15]$. Techniques such as double glow plasma [16], arc ion plating (AIP) [17], application of a hydroxyapatite coating [18], and cryogenic treatment have been successful in improving the wear resistance, adhesion properties and surface hardness of implants [19]. Selective laser melting (SLM) of the surface can be employed to lower porosity and fabricate parts with almost same density as bulk Ti-6A-14V [20]. Among the above described methods, laser induced surface modification techniques have attracted enormous scientific interest. One of the most attractive features of laser processing is that the inherent biocompatibility of the starting material has been found to be not negatively affected during processing [21] and causes minimal contamination which promotes osteointegration and subsequent better implant stability [22-25].

Biocompatibility properties of laser modified surfaces have been extensively studied. Hao et al showed that improved surface roughness and surface energy generated by laser treatment accounted for better wettability characteristics recorded for the material and promoted cell adhesion in biological media [26]. An enhancement of cell spreading and adhesion was 
demonstrated on longitudinally and transversally oriented micro-grooves produced by the laser irradiation of Ti- $6 \mathrm{Al}-4 \mathrm{~V}$ surfaces by Chen et al [27]. Contact guidance was found to promote cell adhesion due to increased interactions between the focal adhesions and the extracellular matrix (ECM) proteins patterned on the laser micro-grooved surfaces. In addition it has been demonstrated that implant surface roughness and porosity have significant effects on the interface response to the implants, mainly with comparatively increased bone formation on rougher surfaces and increased fibrous tissue formation on smooth implants [28]. Grizon et al found that rougher titanium implants produced a stronger bone response compared to smoother implants after a long term implantation [29]. Wennerberg and colleagues demonstrated that wave structures with an average wavelength of $11.6 \mu \mathrm{m}$ and height deviations of $1.4 \mu \mathrm{m}$ were optimal for titanium orthopaedic biomedical implants [22, 30].

In our previous work, we gained an understanding of the mechanisms of formation of surface roughness, melt pool depth, phase transformation, residual strain and chemical composition of the microstructures on $\mathrm{Ti}-6 \mathrm{Al}-4 \mathrm{~V}$ processed via high speed laser processing [31]. The work presented in this paper is focused on an in-depth investigation of the effects of laser surface melting on in-vitro biocompatibility of Ti-6Al-4V by culturing fibroblast and osteoblast cell lines on the surfaces to determine in vitro cytotoxicity, cell viability, cell attachment, proliferation and metabolic activity. Initial knowledge of these effects was gained from the fibroblast cell lines which led to the work performed on the osteoblast cell line relevant to the applications of this material in bone repair.

\section{Materials and methods}

\subsection{Sample preparation}

Laser surface melting was conducted on conventional biomedical titanium alloy Ti-6Al-4V. Composition of the as-received flat annealed alloy samples is listed in table 1. The workpiece, $100 \mathrm{~mm}$ long, $20 \mathrm{~mm}$ wide and $4 \mathrm{~mm}$ high, was grit blasted prior to laser treatment in order to remove surface defects from the alloy. Profilometry measurements of the grit blasted alloy showed an average roughness of $0.56 \pm 0.10 \mu \mathrm{m}$.

Laser surface melting of Ti-6Al-4V alloy was carried out using a $1.5 \mathrm{~kW} \mathrm{CO}$ laser as previously described [29]. In brief, a continuous mode $\mathrm{CO}_{2}$ laser (Rofin DC015, Mechatronic, UK) system was used to irradiate the surface of Ti-6Al-4V alloy at different levels of irradiance $\left(15.72,20.43\right.$ and $\left.26.72 \mathrm{~kW} \mathrm{~mm}^{-2}\right)$ and residence time $(1.08,1.44$ and $2.16 \mathrm{~ms})$ to fabricate laser treated $\mathrm{Ti}-6 \mathrm{Al}-4 \mathrm{~V}$ surfaces. The resulting nine laser processing conditions are summarized in table 2 in terms of applied energy density. The other input parameters (for example, dwelling time, raster frequency, laser spot size, angle of incidence, atmosphere) were kept constant to obtain a detailed understanding of the effect of energy density on the surface properties. The Gaussian laser beam was focused on the work-piece surface providing a laser spot size of $90 \mu \mathrm{m}$. Irradiation was carried out using a raster scan with a partial overlap of $30 \%$ in order to provide for microstructural and compositional homogeneity. 


\begin{tabular}{|c|c|c|c|c|c|c|c|}
\hline Element & $\mathrm{C}$ & $\mathrm{Si}$ & $\mathrm{Fe}$ & $\mathrm{O}$ & $\mathrm{V}$ & $\mathrm{Al}$ & $\mathrm{Ti}$ \\
\hline $\mathrm{wt} \%$ & 0.14 & 0.01 & 0.16 & 0.17 & 3.97 & 6.36 & Bal. \\
\hline \multicolumn{8}{|c|}{$\begin{array}{l}\text { Table 2. Processing paran } \\
\text { Ti-6Al-4V alloy. }\end{array}$} \\
\hline \multicolumn{3}{|c|}{ Sample ID } & \multicolumn{4}{|c|}{ Energy density $\left(\mathrm{J} \mathrm{mm}^{-2}\right)$} & \\
\hline \multicolumn{3}{|c|}{ LSM 1} & \multicolumn{3}{|c|}{33.9552} & & \\
\hline \multicolumn{3}{|c|}{ LSM 2} & \multicolumn{3}{|c|}{44.1288} & & \\
\hline \multicolumn{3}{|c|}{ LSM 3} & \multicolumn{3}{|c|}{57.7152} & & \\
\hline \multicolumn{3}{|c|}{ LSM 4} & \multicolumn{3}{|c|}{22.6368} & & \\
\hline \multicolumn{3}{|c|}{ LSM 5} & \multicolumn{3}{|c|}{29.4192} & & \\
\hline \multicolumn{2}{|c|}{ LSM 6} & & \multicolumn{3}{|c|}{38.4768} & & \\
\hline \multicolumn{2}{|c|}{ LSM 7} & & \multicolumn{3}{|c|}{16.9776} & & \\
\hline \multicolumn{2}{|c|}{ LSM 8} & & \multicolumn{3}{|c|}{22.0644} & & \\
\hline \multicolumn{2}{|c|}{ LSM 9} & & \multicolumn{3}{|c|}{28.8576} & & \\
\hline
\end{tabular}

These parameters were chosen to melt the surface with different degrees of melt superheat. Separate flat areas of $10 \mathrm{~mm}$ by $20 \mathrm{~mm}$ were prepared on the workpiece with each set of laser processing parameters. Argon at a pressure of $200 \mathrm{kPa}$ was used as an assist gas to avoid oxidation during laser processing. The laser beam was kept perpendicular to the workpiece during laser irradiation to maximise the absorbance and ensure uniform conditions for processing [30]. Four work pieces each of $100 \mathrm{~mm}$ were processed with nine different laser processing conditions (each condition being processed onto a separate region of $10 \mathrm{~mm}$ by $20 \mathrm{~mm}$ ). These work pieces were sectioned into individual $10 \mathrm{~mm}$ by $20 \mathrm{~mm}$ samples resulting in four samples per set of laser processing conditions in order to allow repeatability calculation from the biocompatibility testing.

Samples for testing were cut with a diamond cut-off wheel from these work pieces, ultrasonically cleaned in acetone, isopropanol (IPA) and deionised water each for $10 \mathrm{~min}$, and placed in labelled polypropylene bags for storage. Samples were sterilised at $105{ }^{\circ} \mathrm{C}$ for $24 \mathrm{~h}$ in dry state before cell culture testing. Non-laser treated samples, washed according to the same protocol, were used as the control samples in the cellular tests unless otherwise stated.

The influence of the process parameters on the microstructure of the modified surface topology was studied by using scanning electron microscopy (SEM) (Carl Zeiss, EVO LS15, UK) with the aim of providing a better understanding of the process. Surface mean roughness $\left(R_{\mathrm{a}}\right)$ measurements were performed using a stylus profilometer (Civil Instruments TR200, Canada). For detailed microstructure analysis, the surface was sectioned and SEM images of these sections were taken normal to the surface of the sample. Sampling and evaluation lengths used were 0.8 $\mathrm{mm}$ and $4 \mathrm{~mm}$ respectively. 
Five measurements were taken to obtain the average roughness for each sample, according to ISO 4287/4288. Vickers microhardness tests, using a Leitz mini-load tester with diamond indenter, a set load of $500 \mathrm{mN}$, and $30 \mathrm{~s}$ indentation time, were performed on transverse sections through the surface. The contact angles, $\theta$, of deionised water on the untreated and laser treated Ti-6Al-4V were determined in atmospheric conditions using a sessile drop measuring machine (goniometer), FTA 200 angstrom. Dedicated proprietary software was used to measure the wetting angles. Three measurements taken at different positions were averaged to get the final contact angle value for each sample. Element analysis and chemical characterisation were performed with an energy dispersive x-ray spectrometer (EDS), Inca X-Act and Microanalysis suite from Oxford Instruments. The chemical compositions of eight points along a line normal to the surface were measured beginning at $8 \mu \mathrm{m}$ beneath the surface and with each point separated by $8 \mu \mathrm{m}$, thus giving an analysis range of $64 \mu \mathrm{m}$ covering both the untreated and laser melted regions.

\subsection{Resazurin cell viability assay}

The viability of BALB 3 T3 cells (mouse embryonic fibroblast cell line) seeded on the titanium samples was assessed using the resazurin cell viability assay. Resazurin acts as an indicator to measure cell metabolic activity. Viable cells retain the ability to reduce nonfluorescent resazurin to resorufin, which is highly fluorescent at $590 \mathrm{~nm}$ while non-viable cells do not reduce the indicator dye, and thus do not generate a fluorescent signal. The percentage reduction of the resazurin dye by BALB 3T3 cells is dependent on cell number but also on the time available for cell reduction. In order to determine the optimal time points to measure the formation of resorufin, different time points were first investigated in a 24 well microtitre plate. Cells were seeded at a density of 30,000 cells/well and allowed to attach and proliferate for $48 \mathrm{~h}$ by which time the cell number was approximately 120,000 cells/ well.

A final approximate cell density of 120,000 cells per well in a 24 -well plate was maintained throughout all experiments as a standard. This number of cells relates to sub-confluent conditions in the 24-well plate. The medium over the cells was then replaced with medium containing a blue dye, resazurin $(44 \mu \mathrm{M})$. The reduction of resazurin to resorufin was measured at $1 \mathrm{~h}$ intervals. Results presented in this work are the average of three individual experiments from three of the four separate prepared samples for each set of conditions. It was found that the dye reduction remained linear for $3 \mathrm{~h}$ but beyond this point the dye reduction became increasingly non-linear, as shown in the online supplementary figure S1(stacks.iop.org/BMM/10/015007/mmedia).

Measurements beyond this time range would therefore underestimate cell proliferation and would give an inaccurate representation of cell number. Therefore a $3 \mathrm{~h}$ time point was used for all subsequent experiments. Thus, BALB 3 T3 cells were seeded on the laser treated samples in each well at a density of 30,000 cells/well and the reduction of resazurin to resorufin was measured at $3 \mathrm{~h}$ after seeding. For the resazurin assay, the untreated sample was cleaned as described in section 2.1. The positive control was measured from cells in a phosphate buffered 
saline (PBS) (5x)/ trypsin solution (GibcoW, Invitrogen Brasil Ltd, Sao Paulo, SP, Brazil). This positive control was set as the $100 \%$ reduced reazurin reference level for comparison of other sample results. The negative control was measured from cells on cover glass slides (VWR Scientific, USA).

\subsection{MTT assay}

Cytotoxicity tests were performed in accordance with ISO10993-5; 2009 guidelines and included the direct contact, the indirect contact and elution tests with MTT as an endpoint. The in vitro cytotoxicity assessment of the Ti-6Al-4V samples was performed with the mouse embryo fibroblast (NIH/3T3) cell line which was composed of $178 \mathrm{ml}$ Dulbecco's modified Eagles medium (DMEM), $20 \mathrm{ml}$ of fetal calf serum (FCS), $1 \mathrm{ml}$ of penicillin-streptomycin, and $1 \mathrm{ml}$ of amphotericin B. An MTT stock solution $\left(5 \mathrm{mg} \mathrm{ml}^{-1}\right.$ ) was made by dissolving $50 \mathrm{mg}$ of MTT salt in $10 \mathrm{ml}$ of sterile PBS. The solution was filtered through a $0.22 \mu \mathrm{m}$ polyethersulfone (PES) membrane filter, kept in the dark, and refrigerated at $<4{ }^{\circ} \mathrm{C}$. NIH/3T3 cells were seeded at 500,000 cells ml ${ }^{-1}$ in $60 \mathrm{~mm}$ tissue culture plates and incubated at $37{ }^{\circ} \mathrm{C}$ until confluent. Sterile laser treated and untreated $\mathrm{Ti}-6 \mathrm{Al}-4 \mathrm{~V}$ samples were placed in the centre of confluent cultures covering approximately $10 \%$ of the growth area and incubated for a further $24 \mathrm{~h}$ at $37{ }^{\circ} \mathrm{C}$.

Following careful removal of samples with sterile tweezers, and cell incubation in MTT medium $\left(0.5 \mathrm{mg} \mathrm{ml}^{-1}\right)$ for $4 \mathrm{~h}$, the MTT media was carefully aspirated off and dimethyl sulfoxide (DMSO) was added to each well to aid in solubilisation of the crystals. Plates were shaken for 15 $\mathrm{s}$ and incubated at room temperature for $10 \mathrm{~min}$ prior to recording optical densities at $540 \mathrm{~nm}$, with cell viabilities calculated as a percentage of untreated control cells using equation (1) and presented with \pm the standard error of the mean $\left(\mathrm{SEM} \sigma_{\mathrm{M}}\right)$.

$$
\begin{aligned}
& \text { Cell viability (\%) } \\
& \qquad=\frac{\text { Absorbance }_{540 \mathrm{~nm} \text { of treated cells }}}{\text { Absorbance }_{540 \mathrm{~nm} \text { of untreated cells }}} \times 100 .
\end{aligned}
$$

\subsection{Hoechst 33258 DNA pre-osteoblast cell attachment assay}

\subsubsection{Cell attachment and proliferation.}

MC3T3 pre-osteoblast cells were seeded onto titanium samples at a seeding density of $2.5 \times 10^{5}$ cells. The seeded samples were cultured in $1 \mathrm{ml}$ of in standard media ( $\alpha$ MEM media (BioSera) supplemented with $10 \%$ fetal bovine serum (BioSera), 2\% penicillin/streptomycin (Sigma Aldrich), and 1\% l-glutamate (Sigma Aldrich)). At 2 h, 3 and 7 d, the cells were removed using a trypsinethylenediaminetetraacetic acid (EDTA) solution, and digested using papain solution to expose the DNA. Cell number was quantified using Hoechst 33258 DNA assay. Hoechst dye binds to DNA (hence the exposure of DNA required) and fluoresces, which results in higher levels of fluorescence with higher amounts of DNA. Measurements were made using a 
fluorescence spectrophotometer (Varioskan Flash, Thermo Scientific) (excitation: $355 \mathrm{~nm}$; emission: $460 \mathrm{~nm}$ ) and readings were converted to cell numbers using a standard curve. Cell attachment was determined using at $2 \mathrm{~h}$ post seeding and cellular proliferation at 3 and $7 \mathrm{~d}$ post seeding.

\subsubsection{Metabolic activity.}

Metabolic activity of pre-osteoblast cells was evaluated using the alamarBlue ${ }^{\circledR}$ assay. $10 \%$ alamarBlue $^{\circledR}$ solution (Invitrogen, UK) was made using $\alpha$-MEM media (BioSera) and alamarBlue $^{\circledR}$ dye. AlamarBlue ${ }^{\circledR}$ is a compound that is reduced in cells and this reduction results in a colour change of the solution, thereby indicating the cell metabolic activity. The samples were then removed from the media and placed in 24 well plates with $1 \mathrm{ml}$ of $10 \%$ alamarBlue ${ }^{\circledR}$ solution in each well. The samples were then incubated at $37{ }^{\circ} \mathrm{C}$ and $5 \% \mathrm{CO}_{2}$ for $4 \mathrm{~h}$. They were then transferred back to 24 well plates with $1 \mathrm{ml}$ of media in each well, and the alamarBlue ${ }^{\circledR}$ solution pipetted out in $100 \mu \mathrm{l}$ triplicate on 96 well plates and read with a spectrophotometer at 540 and $620 \mathrm{~nm}$ absorbance. This process was repeated at $24 \mathrm{~h}(1 \mathrm{~d}), 96 \mathrm{~h}(3 \mathrm{~d})$ and $168 \mathrm{~h}(7 \mathrm{~d})$ to assess cell metabolism.

\subsection{Statistical analysis}

One way repeated analysis of variance (ANOVA), followed by Holm-Sidak multiple comparisons, were performed to compare data. T-tests were also used to compare the treated and untreated samples. Error bars on figures report data standard deviations and $p<0.05$ was used as the probability value to determine significance, unless otherwise stated.

\section{Results}

\subsection{Surface characteristics}

The effect of laser processing parameters on resulting microhardness with respect to depth from the laser treated surface is shown in figure 1. This SEM image shows the microstructure in the transverse (perpendicular) direction to the sample surface and the associated laser affected microstructural region. A microhardness value of $760 \mathrm{HV}$ was achieved for laser treated surfaces, accounting for an increase in hardness of up to $67 \%$ compared to the as-received alloy. The back scattered image of Ti-6Al-4V surface $(b)$ before and $(a)$ after laser surface melting is shown in figure 1 (inset). The phase structure transformed from the typical $\alpha$ (dark regions) $+\beta$ (lighter regions) structure before processing into a fine martensite structure after processing due to the low residence times used in the experiments which resulted in high cooling rates. An associated reduction in $\beta$ phase from an average of $29 \%$, in the non-laser treated material, to an average of $21 \%$, in the laser treated material, was previously recorded via XRD [31]. No observable voids, inclusions, or pits were present. 


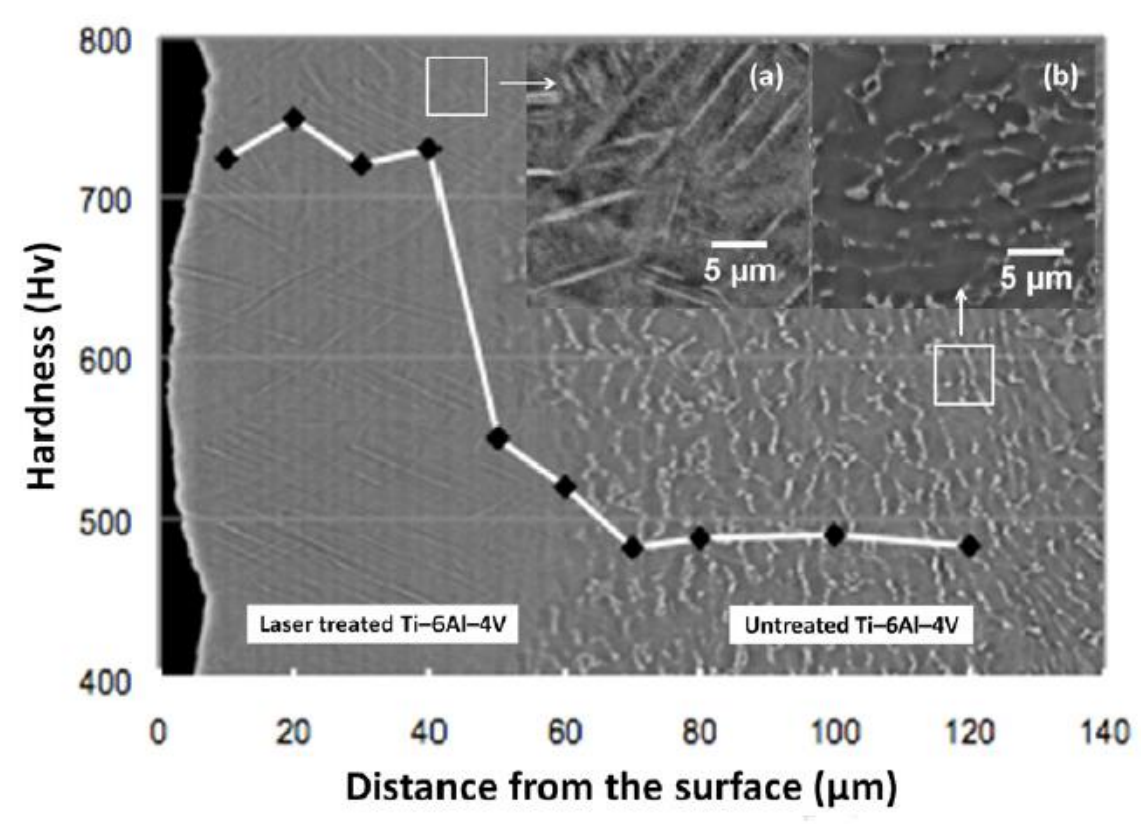

Figure 1. SEM image of the sample microstructure on a section taken normal to the surface of the sample, corresponding microhardness results shows increased hardness within the laser surface modified region compared to the bulk non-treated region. Inset: back scattered electron microstructural images of $(a)$ laser treated and $(b)$ untreated Ti-6Al-4V.

After high speed laser treatment, regular processed tracks were observed revealing phase transformation in the modified layer with no evidence of ablation of the surface. This crack elimination is attributed to the high speed processing, ensuring minimal thermal stress exerted on the surface thus avoiding crack development. A detailed investigation of the influence of the process parameters on the surface topology has been reported previously [31]. The laser treated surfaces had average roughness values between 1.39 and $2.73 \mu \mathrm{m}$ depending on the process parameters, with the lower roughness values occurring at the higher irradiance values for the range of irradiance levels investigated; refer to online supplementary table S1(stacks.iop.org/ BMM/10/015007/mmedia).

Chemical compositions of eight points covering both the untreated and laser melted regions were measured. Figure 2 shows the variation in weight percent of the titanium (Ti) element for samples LSM 3, LSM 6 and LSM 9. This micrograph also highlights changes in microstructure of the laser surface modified sample at the corresponding distances. Within the laser treated region, the titanium element composition is uniform at approximately $90 \%$ compared to the relatively non-homogenous titanium distribution within the bulk alloy. The same trend was found for the aluminium alloying element in the online supplementary figure S1(stacks.iop.org/ BMM/10/015007/mmedia). 


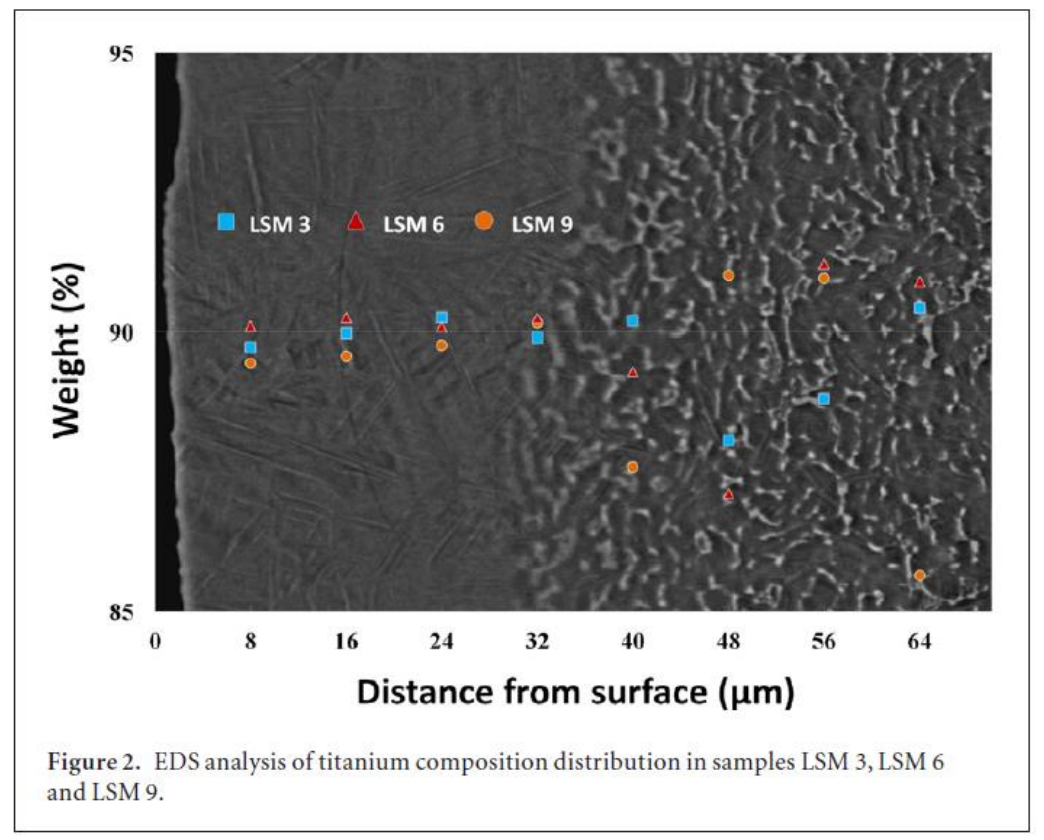

\subsection{Resazurin cell viability assay}

Subsequent to BALB 3 T3 cells being seeded at a density of 30,000 cells on laser treated samples in three groups, metabolic activity of cells was investigated after $3 \mathrm{~h}$ as a function of reduced resazurin to resorufin. The effects of laser treated surface on the reduction of resazurin are shown in figure 3. Results are represented as a percentage of the untreated control $\pm \%$ of standard deviation of four individual experiments.

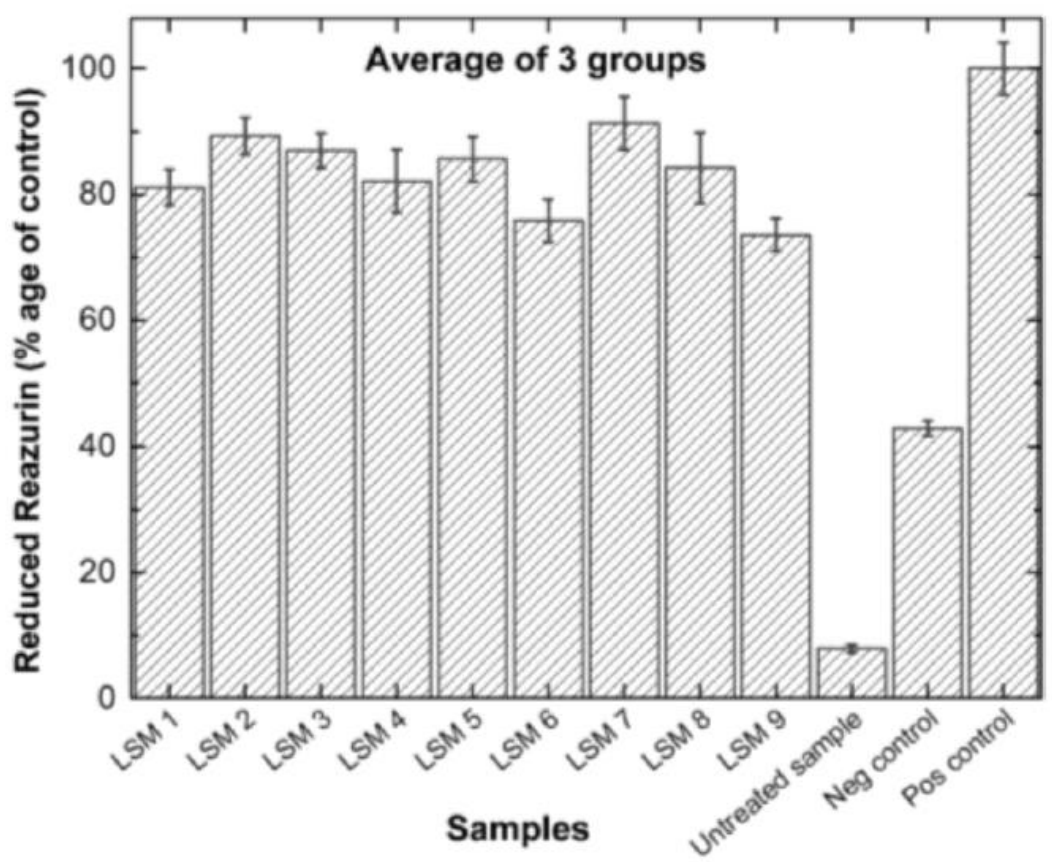

Figure 3. Average results of resazurin reduction in all three groups as a percentage of the control at $3 \mathrm{~h}$ after seeding. 
The measurement of reduced percentage of resazurin indicates the viability of cells and the integrity of mitochondrial function. Thus, these results clearly show preferential cell growth and cell viability on the laser treated surfaces. The variation in the amount of reduced resazurin could be attributed to the difference in average roughness between the laser treated samples (average $R_{\mathrm{a}}$ of $1.8 \mu \mathrm{m}$ ) and the non-treated sample (average $R_{\mathrm{a}}$ of $0.56 \mu \mathrm{m}$ ). The results from all three groups are reported in the online supplementary figures S2-S4(stacks.iop.org/ BMM/10/015007/mmedia).

\subsection{MTT assay}

\subsubsection{Direct contact}

The MTT assay determines the ability of viable cells to convert the soluble tetrazolium salt (MTT) into a purple formazan precipitate which can be quantified spectrophotometrically, and is directly proportional to the number of viable cells. Figure 4 represents the results for MTT viability assessment of $\mathrm{NIH} / 3 \mathrm{~T} 3$ fibroblast cells following $24 \mathrm{~h}$ exposure to the samples.

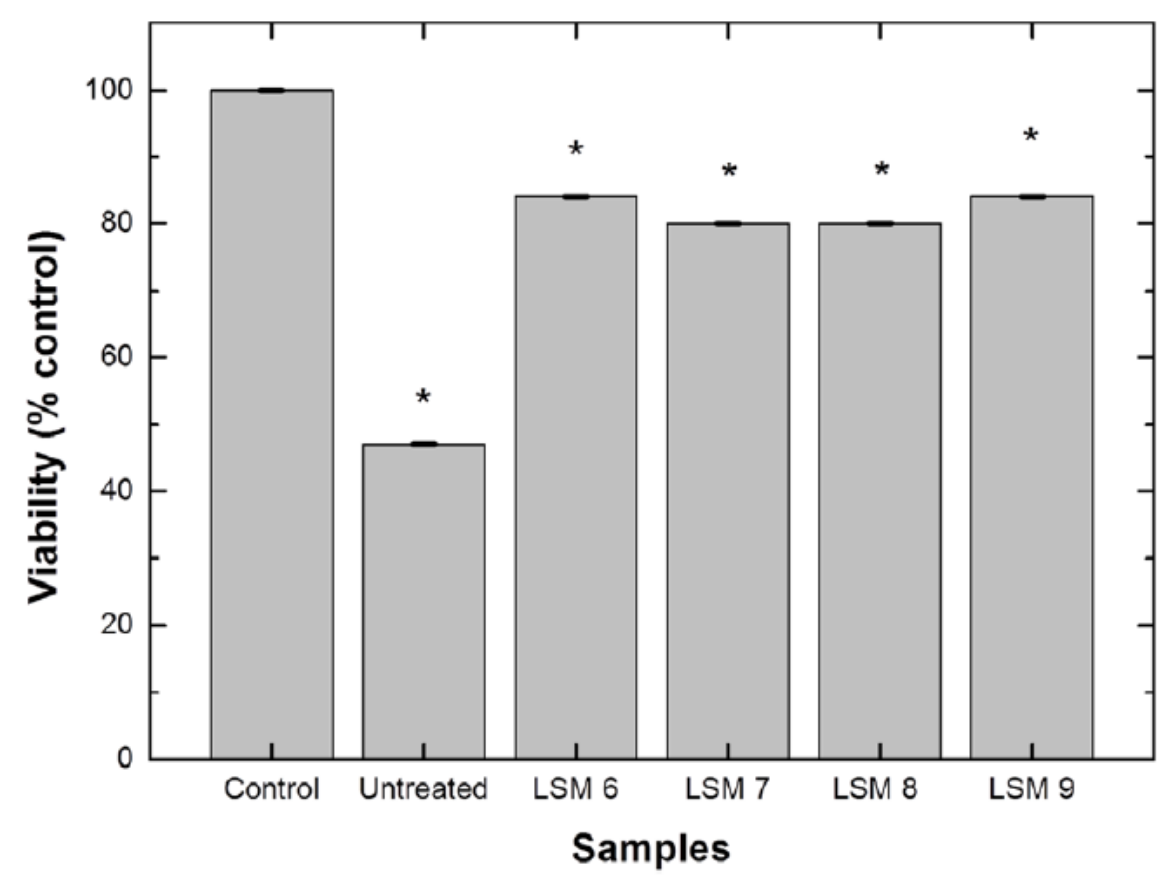

Figure 4. Effect of Ti-6Al-4V samples in direct contact with NIH/3T3 fibroblasts for $24 \mathrm{~h}$ using the MTT cell viability assay as a measure of toxicity $\left({ }^{*} p<0.05\right)$

Each result is the mean of three separate experiments where $n=3 \pm \sigma_{\mathrm{M}}$, (* denotes a significant difference from the control, $\left.{ }^{*} p<0.05\right)$. A high degree of reproducibility was achieved as indicated by the relatively small error bars. Laser treated samples showed a significant $(p<0.05)$ inhibition of formazan production with viability of $\sim 80 \%$ compared to the untreated samples 
which presented viability values below $50 \%$ at $24 \mathrm{~h}$ exposure. The results clearly indicate that the laser treatment increased the cell viability as compared to the untreated samples and had a positive impact on reducing the cytotoxicity of the Ti-6Al-4V surfaces.

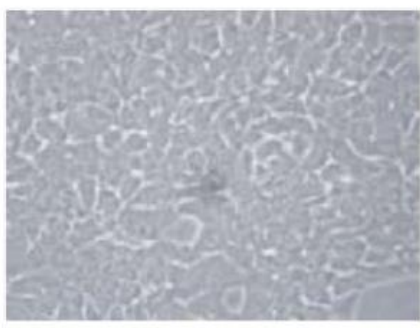

(a)

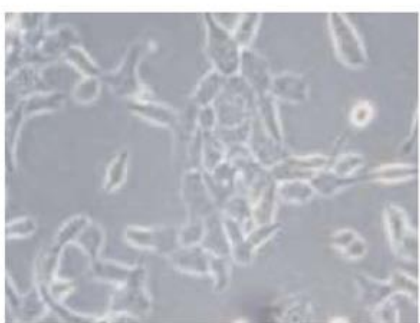

(b)

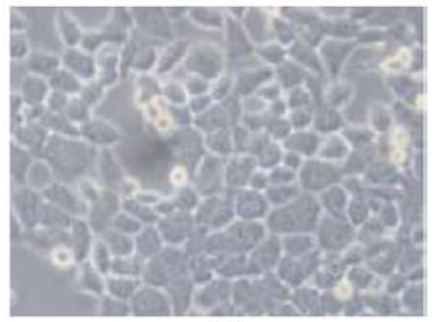

(c)

Figure 5. Pictures of NIH/3T3 mouse embryo fibroblasts indicating number and morphology of cells after $24 \mathrm{~h}$ of contact with the $(a)$ control, $(b)$ untreated, and $(c)$ laser modified samples (LSM8 - representative of laser treated samples). Mag.: $10 \times$.

Microscopic examinations were carried out on cells exposed to the control, untreated and the laser treated sample surfaces; see figure 5. Exposure to untreated surfaces resulted in detachment and death of numerous cells as indicated by the deteriorated cell monolayer compared to the control; see figures $5(a)$ and $(b)$. In contrast, the majority of NIH/3T3 cells exposed to the laser modified surfaces were still attached and only minor morphological changes, such as detachment of single cells, was observed; see figure $5(c)$. Cell viability percentage was not found to be significantly affected for the range of roughness $\left(R_{\mathrm{a}}\right.$ of $\left.1.3-2.7 \mu \mathrm{m}\right)$ and contact angels $\left(25-60^{\circ}\right)$ provided within the laser processed samples.

\subsubsection{Elusion test.}

Figure 6 shows the effect of various concentrations of untreated and laser melted Ti-6Al-4V sample extracts in contact with NIH/3T3 fibroblasts for $24 \mathrm{~h}$ using the MTT cell viability assay as a measure of toxicity. Each data point is the mean of three separate experiments where $n=18$ $\pm \sigma_{\mathrm{M}}$. All samples produced a dose dependent decrease in viability. High extract concentrations resulted in up to $20 \%$ inhibition of formazan production while low concentrations exerted only slight cytotoxic behaviour. In general, laser treated samples showed high cell viability compared to the non-treated samples.

\subsection{Hoechst 33258 DNA pre-osteoblast cell attachment assay}

\subsubsection{Cell attachment and proliferation}

Cell attachment after $2 \mathrm{~h}$ was with the rage of $15-30 \%$ of the number of cells originally seeded for all samples. The differences in cell number on day 3 and day 7 are shown in figure 7 . 

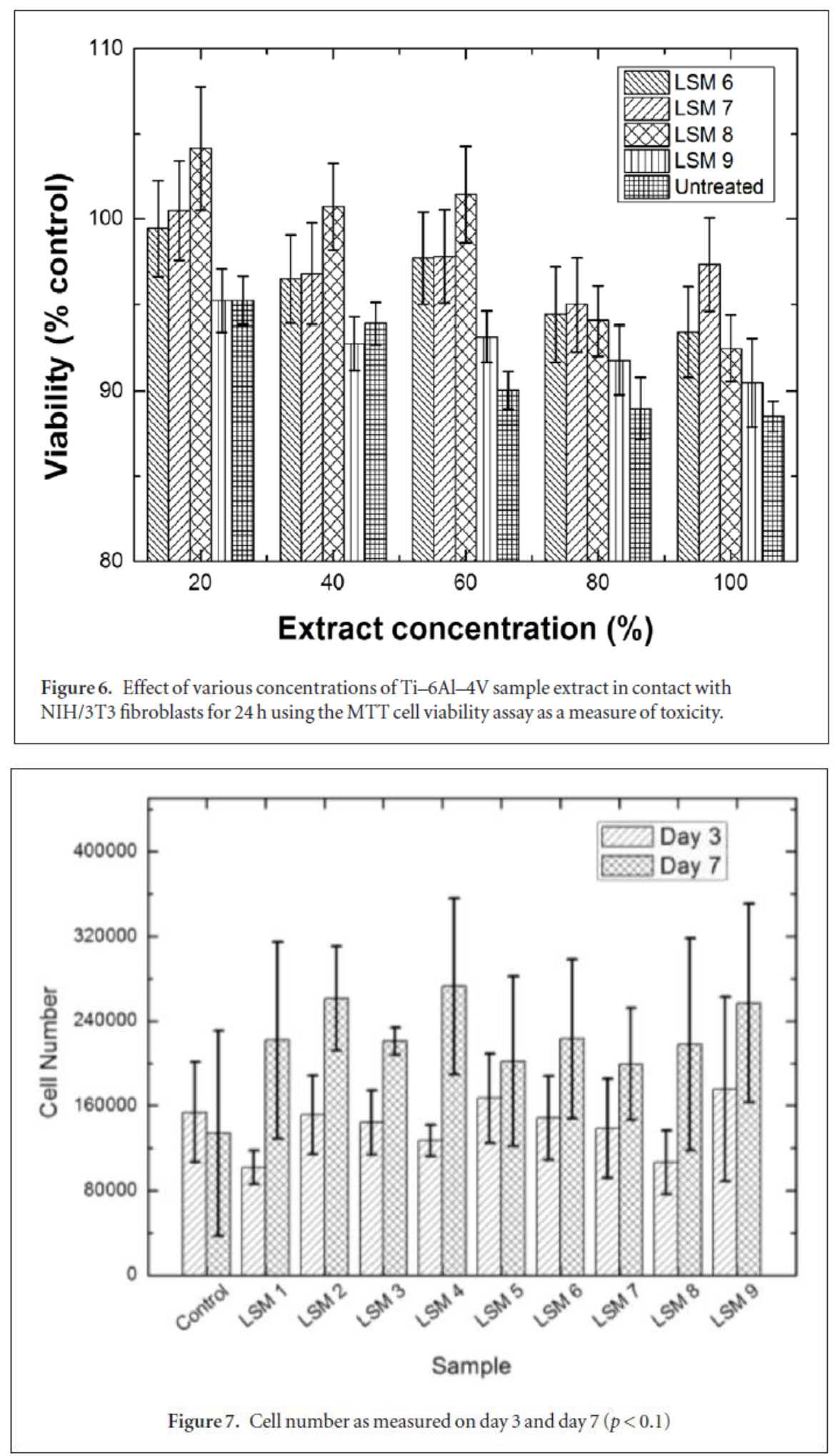

One way ANOVA calculations showed no significant difference in cell number at day 3, but there were significantly higher numbers of cells at day 7 for all treated samples compared to the 
untreated controls $(\mathrm{p}<0.1)$. This clearly suggests that the laser treated surfaces favoured cell metabolism which led to the significant increase in the cell number. The differences between the properties of the treated samples were not large enough to show significant differences in cell metabolism and proliferation. It is suggested that further studies be undertaken with a wider range of laser processing conditions and to develop an assay for evaluation of cell metabolism and proliferation over a longer time frame.

\subsubsection{Metabolic activity.}

The effect of the samples on pre-osteoblast cell proliferation is shown in figure 8. One way ANOVA for each set of data demonstrated that there is no significant difference between cell proliferation levels on the laser treated samples. However, the difference between the control (untreated sample) and the laser treated samples was significant $(p<0.05)$. This demonstrates that there was enhancement of cell metabolic activity on the laser treated samples compared to untreated control Ti-6Al-4V samples. Furthermore 90\% confidence intervals showed that there was a significant difference between untreated control and the treated samples for the lowest time point.

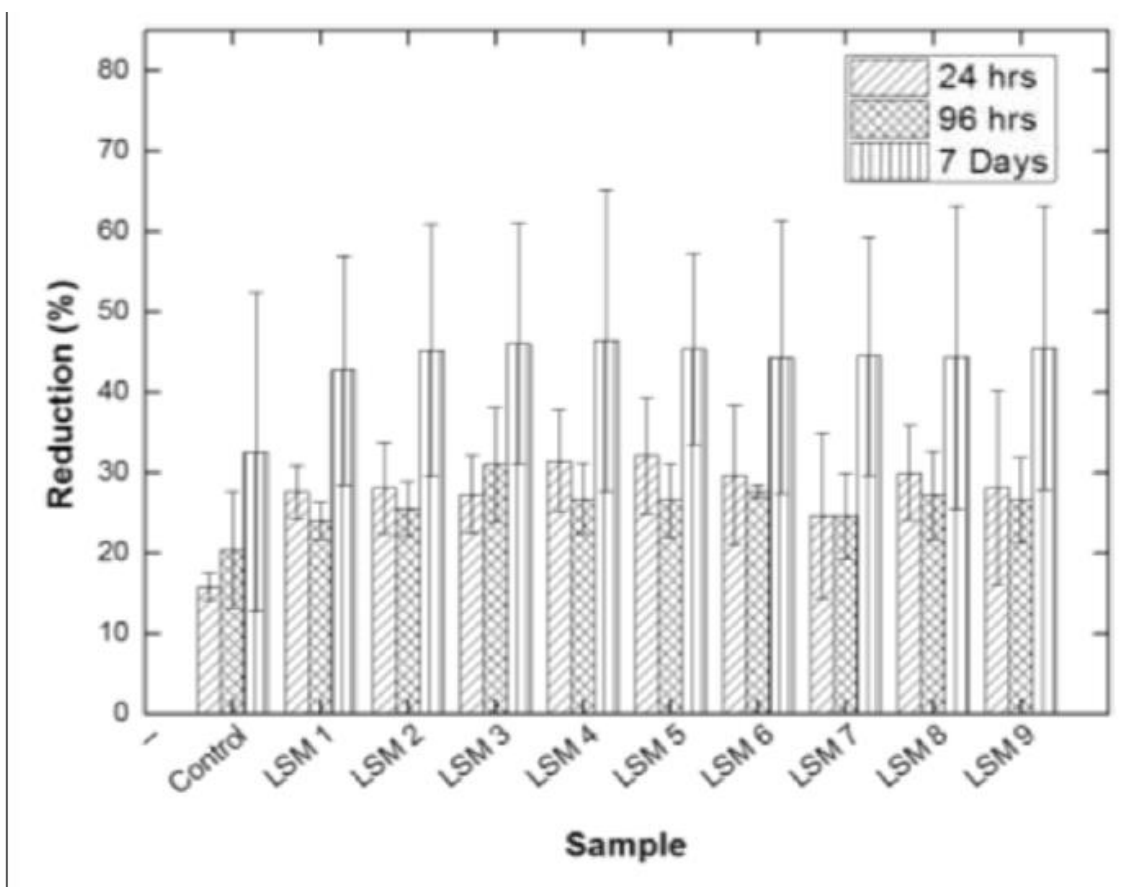

Figure 8. Trends of metabolic activity as percent reduction for samples at $24 \mathrm{~h}, 96 \mathrm{~h}$, and $7 \mathrm{~d}$ with respect to sample type and to time. $90 \%$ confidence intervals are indicated for the control and LSM 3 (representative of laser treated samples). 


\section{Discussion}

The nature of implant surface is known to play a direct role in determining the biological response. The results of this study demonstrate that cellular response to bulk Ti-6Al-4V alloy can be improved substantially by the laser surface melting method employed. Unlike other surface modification methods, the formation of structures via laser surface melting in this work were achieved with set levels of irradiance, high speed processing, low residence times, and assisting gas. The processing parameters were carefully chosen so that energy densities did not exceed levels that would induce ablation of surface material and hence would exert minimal thermal stress in order to avoid the development of surface cracks. Samples with an average roughness value $\left(R_{\mathrm{a}}\right)$ between 1.39 and $2.73 \mu \mathrm{m}$ were fabricated via this technique compared to the non-laser treated sample roughness of $0.56 \mu \mathrm{m} R_{\mathrm{a}}$. Cell adhesion, proliferation, viability and metabolic activity of fibroblast cells were evaluated in order to estimate the in vitro cycotoxicity response to the laser treated surfaces.

Direct contact analysis showed improved cytotoxicity behaviour in laser treated samples compared to the untreated control. Overall the viability of the NIH/3T3 monolayer did not significantly vary from the untreated control monolayer indicating minimal loss of viability following treatment with extracts prepared from laser treated samples seven to nine. On the other hand, the highest tested concentration of extracts obtained from sample six and untreated samples induced a slight but significant $(p<0.05)$ loss in cell viability indicating the possibility of detrimental leachates being present; see figure 6 . The release and accumulation of metallic ions over time by the way of passive dissolution or another process involving wear can potentially lead to discoloration of the surrounding tissue, an inflammatory reaction, and lead to osteolysis $[32,33]$. However, results from the elution tests indicate that although statistically significant reductions in cell viability were observed upon exposure to extracts from untreated samples, cell viability remained high for all samples and at an acceptable level for biomedical applications, according to ISO10993-5; 2009. Initial positive results from the fibroblast cell lines led to the work performed on the osteoblast cell line which is relevant to the usage material in bone repair applications.

Cell attachment and proliferation of MC3T3 preosteoblastic cells in contact with the nontreated control and the laser treated samples were evaluated at day 3 and day 7 . The results showed that the laser surface melting did not adversely affect the initial cell attachment on the implant surface. No significant difference was detected in cell number at day 3, however cell number increased to a significantly higher level within the laser treated samples at day 7 . These results are in agreement with similar studies reporting the positive effect of laser modification of titanium alloys on the biological response $[34,35]$. Some groups report a significant difference in cell attachment with level of roughness [36], which was not found within the range of roughness encountered from the current study. An average 30\% cell attachment on laser treated titanium alloys was observed, and this value was independent of roughness and contact angle of the surface within the ranges investigated. The explanation of this lack of difference in cell 
attachment levels between laser treated samples could possibly be due to the small variation in $R_{\mathrm{a}}$ values among the samples examined (between 1-3 $\mu \mathrm{m}$ ).

Metabolic activity was recorded after 1, 3 and $7 \mathrm{~d}$. At day 1 time point, a significantly higher metabolic activity was recorded for the laser treated samples in comparison to the non-treated control. At day 3 positive metabolic activity was recorded while at day 7 metabolism was significantly higher in many of the laser treated samples compared to the day 3 recoded levels. While average results show increasing cell proliferation and metabolism for the laser treated samples as time progresses, data error bars can also be seen to overlap in some cases. Further studies could examine more samples to reduce these as well as cell metabolism and proliferation over a longer time frame (i.e. greater than $7 \mathrm{~d}$ ) and for a larger range of surface roughness levels. However, higher average cell attachment and metabolic activity on treated samples compared to the untreated controls was confirmed with alamarBlue ${ }^{\circledR}$ assay which indicates the higher bioactivity of the treated surfaces [23].

Some differences were recorded for the effect of the laser processing parameters for specific cell line responses, however these were relatively minor compared to the improved benefits of the laser treated surfaces in comparison to the non-laser treated surfaces. The results in this paper have shown that the laser treatment employed substantially improves cell adhesion, proliferation, and metabolic activity for both fibroblast and pre-osteblastic, relative to non-laser treated surfaces for Ti-6Al-4V. In addition, the laser treated surfaces show better long term cell proliferation and cellular metabolic activity for pre-osteoblastic cells. The laser treated surfaces had increased roughness, reduced $\beta$ phase ( $8 \%$ reduction), and increased microhardness $(250 \mathrm{HV}$ increase) in comparison to the non-laser treated surface. Several studies attribute reduced $\beta$ phase (i.e. transformed $\mathrm{Ti}$ martensitic structure) in the laser-modified layer to increased corrosion resistance due to enhanced chemical inertness [37, 38].

It is therefore expected that this technique of surface melting has tremendous potential to significantly improve the biocompatibility of titanium implants in vivo. Other factors that would be altered and which may affect cellular response include resultant changes in oxide layer formation [39] and grain structure (including orientation and size). Within the range of tested parameters, decisions regarding the optimum parameters should also be based on surface durability results such as life times as determined from corrosion or tribological testing [31].

\section{Conclusions}

Biocompatible Ti-6Al-4V alloy surfaces have been fabricated by laser surface melting using a $\mathrm{CO}_{2}$ laser in an argon gas atmosphere. The laser treated surfaces showed an enhanced cell growth and proliferation compared to the untreated bulk Ti-6Al-4V surface. Metabolic activity and cell viability studies demonstrated improved cellular responses in contrast with control experiments. Our experiments showed that laser fabricated $\mathrm{Ti}-6 \mathrm{Al}-4 \mathrm{~V}$ alloy surfaces provided significantly enhanced cellular attachment and viability above that of the nonprocessed alloy, and

thus are promising candidates to be utilised as biological implants. Significantly better results for 
specific laser processing parameters and for specific cell assays were recorded indicating the potential for implementation of optimised laser processing parameters in order to achieve optimum biocompatibility. Further investigations to better understand cell growth mechanisms could include a wider range of examination for laser processing parameters and a design of experiments to deconvolve of the effects from surface chemistry, roughness, surface area, and grain structure (including orientation and size). However, the results presented here indicate that significantly increased biocompatibility has resulted from the investigated laser treatments and thus this laser surface melting treatment shows great potential to provide improved biocompatibility of titanium implants in vivo.

\section{Acknowledgments}

The authors sincerely thank the Office of Vice President of Research (DCU), National Access Program (Tyndall), the Physicians Award Fund (RCSI), and SFI grant number 12/IA/1576 for the financial support for this work.

\section{References}

[1] Malchau H, Herberts P, Eisler T, Garellick G and Söderman P 2004 The Swedish Total Hip Replacement Register J. Bone Joint Surg. Am. 86-A 363-82

[2] Amstutz H C, Campbell P, Kossovsky N and Clarke I C 1992 Mechanism and clinical significance of wear debris-induced osteolysis Clin. Orthop. Relat. Res. 276 7-18

[3] Nag S and Banerjee R 2012 Fundamentals of medical implant materials ASM Handbook, Materials for Medical Devices vol $\mathbf{2 3}$ ed R J Narayan (Materials Park, OH: ASM International) pp 6-17

[4] González J E G and Mirza-Rosca J C 1999 Study of the corrosion behavior of titanium and some of its alloys for biomedical and dental implant applications J. Electroanal. Chem. 471 $109-15$

[5] Grosgogeat B, Reclaru L, Lissac M and Dalard F 1999 Measurement and evaluation of galvanic corrosion between titanium/Ti6Al4V implants and dental alloys by electrochemical techniques and auger spectrometry

Biomaterials 20 933-41

[6] Lowenberg B F, Lugowski S, Chipman M and Davies J E 1994 ASTM-F86 passivation increases trace element release from Ti6Al4V into culture medium J. Mater. Sci. 5 467-72

[7] Park J W, Jang J H, Lee C S and Hanawa T 2009 Osteoconductivity of hydrophilic microstructured titanium implants with phosphate ion chemistry Acta Biomater. 
$52311-21$

[8] Sul YT, Johansson C, Byon E and Albrektsson T 2005 The bone response of oxidized bioactive and non-bioactive titanium implants Biomaterials 26 6720-30

[9] Yuhua L, Chao Y, Haidong Z, Shengguan Q, Xiaoqiang L and Yuanyuan L 2014 New developments of Ti-based alloys for biomedical applications Materials 7 1709-800

[10] Velasco-Ortega E, Jos A, Cameán A M, Pato-Mourelo J and Segura-Egea J J 2010 In vitro evaluation of cytotoxicity and genotoxicity of a commercial titanium alloy for dental implantology Mutat. Res. 702 17-23

[11] Faria A C L, Rosa A L, Rodrigues R C S and Ribeiro R F 2008 In vitro cytotoxicity of dental alloys and cpTi obtained by casting

J.Biomed. Mater. Res. B 85 504-8

[12] Guan X, Lu Z and Wang L 2011 Achieving high tribological performance of graphite-like carbon coatings on Ti6Al4V in aqueous environments by gradient interface design Tribol.

Lett. 44 315-25

[13]Liu P, Smits J, Ayers D C and Song J 2011 Surface mineralization of Ti6Al4V substrates with calcium apatites for the retention and local delivery of recombinant human bone morphogenetic protein Acta Biomater. 7 3488-95

[14]Ben N J, Liang W P, Ren B L and Miao Q 2012 Tribological behaviors of Ti6Al4V with surface plasma molybdenized Mater. Sci. Forum 704-705 1253-8

[15] Qin L, Yang K K, Wang S and Tang B 2012 Repeated impact resistance of Cr-Mo surface alloying layers on Ti6A14V alloy Adv. Mater. Res. 399-401 1958-61

[16] Xua Z, Liuc X, Zhang P, Zhanga X, Zhanga G and Hea Z 2012

Double glow plasma surface alloying and plasma nitriding

Surf. Coat. Techol. 206 3223-9

[17] Chang Z K, Wan X S, Pei Z L, Gong J and Sun C 2011 Microstructure and mechanical properties of $\mathrm{CrN}$ coating deposited by arc ion plating on Ti6Al4V substrate Surf. Coat. Technol. 205 4690-6

[18] Vangoelue S Y, Bayrak O, Kovaci H, Yildirim O S, Akguen A and Ayhan C 2011 Investigation of the pull-out strengths of

Ti6Al4V cortical screws oxidized with various methods

J.Biomech. 445

[19] Balla V K et al 2011 Quasi static torsional deformation behavior of porous Ti6Al4V alloy Mater. Sci. Eng. C

31 941-9

[20] Song B, Dong S, Zhang B, Liao H and Coddet C 2012 Effects of processing parameters on microstructure and mechanical property of selective laser melted Ti6Al4V Mater. Des.

35 120-5

[21] Bandyopadhyay A, Balla V, Roy M and Bose S 2011 Laser surface modification of metallic biomaterials J. Min. Met.

Mater. 63 94-9 
[22] Gaggl A, Schultes G, Muller W D and Karcher K 2000 Scanning electron microscopical analysis of laser-treated titanium implant surfaces-a comparative study Biomaterials

21 1067-73

[23] Hao L and Lawrence J 2006 Laser Surface Treatment of

Bio-implant Materials (UK: Wiley)

[24] Mirhosseini N, Crouse P L, Schmidth M J J, Li L and Garrod D 2007 Laser surface microtexturing of Ti-6Al-4V substrates for improved cell integration Appl. Surf. Sci.

$2537738-43$

[25] Ul Ahad I, Bartnik A, Fiedorowicz H, Kostecki J, Ciach T and Brabazon D 2014 Surface modification of polymers for biocompatibility via exposure to extreme ultraviolet (EUV) radiation J. Biomed. Mater. Res. A 102 3298-310

[26] Hao L, Lawrence J and Li L 2005 Manipulation of the osteoblast response to a Ti-6Al-4V titanium alloy using a high power diode laser Appl. Surf. Sci. 247 602-6

[27] Chen J, Ulerich J P, Abelev E, Fasasi A, Arnold C B and Soboyejo W O 2009 An investigation of the initial attachment and orientation of osteoblast-like cells on laser grooved Ti-6Al-4V surfaces Mater. Sci. Eng. C 29 1442-52

[28] Deligianni D D, Katsala N, Ladas S, Sotiropoulou D, Amedee J and Missirlis Y F 2001 Effect of surface roughness of the titanium alloy $\mathrm{Ti}-6 \mathrm{Al}-4 \mathrm{~V}$ on human bone marrow cell response and on protein adsorption Biomaterials

22 1241-51

[29] Grizon F, Aguado E, Huré G, Baslé M F and Chappard D 2002 Enhanced bone integration of implants with increased surface roughness: a long term study in the sheep J. Dent.

30 195-203

[30] Hallgren C, Reimers H, Chakarov D, Gold J and Wennerberg A 2003 An in vivo study of bone response to implants topographically modified by laser micromachining

Biomaterials 24 701-10

[31] Chikarakara E, Naher S and Brabazon D 2012 High speed laser surface modification of Ti6Al-4V Surf. Coat. Technol.

206 3223-9

[32] Scales J 1991 Black staining around orthopaedic implants J. Bone. Joint Surg. 73-B 534-6

[33] Granchi D, Cenni E, Trisolino G, Giunti A and Baldini N 2006 Sensitivity to implant materials in patients undergoing total hip replacement J. Biomed. Mater. Res. B 77B 257-64

[34] Vlacic-Zischke J, Hamlet S M, Friis T, Tonetti M S and Ivanovski S 2011 The influence of surface microroughness and hydrophilicity of titanium on the up-regulation of TGF $\beta / B M P$ signalling in osteoblasts Biomaterials 32 665-71

[35] Chung T, Liu D and Wang S 2003 Enhancement of the growth of human endothelial cells by surface roughness at nanometer scale Biomaterials 24 4655-61

[36] Jayaraman M, Meyer U, Bühner M, Joos U and Wiesmann H 2004 Influence of titanium surfaces on attachment of osteoblast-like cells in vitro Biomaterials 25 625-31 
[37] Atapour M, Pilchak A, Frankel G S, Williams J C, Fathi M H and Shamanian M 2010 Corrosion behavior of $\mathrm{Ti}-6 \mathrm{Al}-4 \mathrm{~V}$ with different thermomechanical treatments and microstructures Corrosion 66065004

[38] Yue T M, Cheung T M and Man H C 2000 The effects of laser surface treatment on the corrosion properties of Ti-6Al-4V alloy in Hank's solution J. Mater. Sci. Lett. 19 205-8

[39] Ask M, Lausmaa J and Kasemo B 1989 Preparation and surface spectroscopic characterization of oxide films on Ti6Al4V Appl. Surf. Sci. 35 283-301 